\title{
MORTE, SIGNIFICAÇÃO E OS LIMITES DA REPRESENTAÇÃO: \\ UM PERCURSO DERRIDIANO DE HUSSERL A HEIDEGGER
}

\section{DEATH, MEANING AND THE LIMITS OF REPRESENTATION: A DERRIDIAN WAY FROM HUSSERL TO HEIDEGGER}

\author{
Ricardo Avalone Athanásio Dantas. ${ }^{1}$ \\ Gustavo Silvano Batista ${ }^{2}$
}

Resumo: Partindo do pressuposto segundo o qual a atitude fenomenológica é constituída de uma simultaneidade entre o processo subjetivo e imanente e o próprio objeto em sua constituição na imanência, pretende-se neste artigo investigar as razões pelas quais Husserl não a concretiza plenamente. Assim, 1) ao considerar que o objeto só é possível à medida que o mesmo está no horizonte da intencionalidade, concebendo o ato intencional como constituinte da aparição do objeto; e 2) ao buscar fundamentar o conhecimento na consciência ideal/transcendental que constitui a idealidade capaz de salvar o domínio da presença na repetição - de uma presença que não corresponde estritamente a nada que existe no mundo, mas é correlata dos atos de repetição ideais. Qual a causa dessa dificuldade, desse (aparente) paradoxo? Husserl manteve-se preso ao esquema empirista (Lévinas)? Operou um recorte do a priori lógico no interior mesmo do a priori geral da linguagem, repetindo por outros meios a intenção original da metafísica, afirmando assim o ser como presença (Derrida)? Ou talvez um descuido originário por parte de Husserl com relação ao campo temático da fenomenologia e a tarefa de ver e explicitar a existência em seu ser (Heidegger) o impediu de perceber que o que provavelmente está em jogo naquilo que abre quando se assegura o movimento da idealização é uma certa relação do existente com sua morte (Derrida)? Analisaremos as hipóteses levantadas considerando privilegiadamente o modo como os limites da representação se manifestam a partir da radicalização do questionamento acerca da relação entre significação e morte.

Palavras-chave: Husserl; Heidegger; Derrida; morte; significação; representação.

\footnotetext{
${ }^{1}$ Mestre em Filosofia - UFPI. Professor da SEDUC-Maranhão. E-mail: ricardo.avalone@gmail.com

2 Professor do Programa de Pós-Graduação em Filosofia - UFPI. Departamento de Filosofia da UFPI. E-mail: gustavosilvano@ufpi.edu.br
} 


\begin{abstract}
:
Starting from the supposition that the phenomenological attitude consists of simultaneity between the subjective and immanent process and the object itself in its constitution in immanence, this article intends to investigate the reasons why Husserl does not fully realize it. Thus, 1) when considering that the object is only possible as long as it is on the horizon of intentionality, conceiving the intentional act as a constituent of the object's appearance; and 2) by seeking to base knowledge on the ideal / transcendental consciousness that constitutes the ideality capable of saving the domain of presence in repetition - of a presence that does not strictly correspond to anything that exists in the world, but is correlated with ideal repetition acts. What is the cause of this difficulty, this (apparent) paradox? Did Husserl remain bound by the empiricist scheme (Lévinas)? Did you operate a section of the logical a priori within the general a priori of language, repeating by other means the original intention of metaphysics, thus affirming being as presence (Derrida)? Or perhaps an original carelessness on the part of Husserl in relation to the thematic field of phenomenology and the task of seeing and making explicit the existence in his being (Heidegger) prevented him from realizing that what is probably at stake in what he opens when the movement is secured Is idealization a certain relationship between what exists and its death (Derrida)? We will analyze the hypotheses raised considering privilegedly the way in which the limits of representation are manifested from the radicalization of the questioning about the relationship between meaning and death.
\end{abstract}

Keywords: Husserl; Heidegger; Derrida; death; meaning; representation. 


\section{Husserl, os signos e o problema do conhecimento}

Nas Investigações lógicas, Husserl propõe-se a realizar uma investigação epistemológica rigorosa, de tal forma rever o caráter intrinsecamente científico de toda ciência a partir de uma crítica radical à noção de objetividade, própria de toda ciência. Segundo suas próprias palavras, um tal tipo de pesquisa deve satisfazer o princípio da ausência de pressupostos ${ }^{3}$. O objetivo dessa teoria consiste precisamente na "tomada de consciência do sentido do conhecimento" do qual resulte não "qualquer opinião, mas antes um saber evidente" (HUSSERL, 2014, p. 18) e, por conseguinte, ainda não questionado. Em linhas gerais, do ponto de vista de Husserl, há um dogmatismo constitutivo na ciência da sua época.

Ora, tal tomada de conhecimento deve realizar-se necessariamente, para Husserl, "enquanto pura intuição de essência, sobre a base exemplar de vivências de conhecimento e de pensamento dadas" (HUSSERL, 2014, p. 18). Nesse sentido, “[a] ausência científico-natural, psicológica de pressupostos" é o que Husserl pretende satisfazer com suas pesquisas, considerando que

as verdadeiras premissas dos resultados que se pretendem devem residir em proposições que satisfaçam a exigência de que aquilo que asserem permita uma justificação fenomenológica adequada, portanto, preenchimento através da evidência no sentido mais rigoroso do termo; mais ainda, que as proposições devam ser sempre tomadas apenas no sentido em que foram intuitivamente estabelecidas (HUSSERL, 2014, p. 20).

Com o intuito de retomar o início do projeto fenomenológico nas Investigações Lógicas, a primeira etapa deste texto consistirá no estabelecimento de uma distinção essencial entre expressão e signo - e é precisamente esta etapa do percurso husserliano que nos interessa aqui. O foco da nossa atenção nesse ponto, ou seja, a pergunta que guia a nossa própria pesquisa, portanto, é derridiana, e se apresenta diante da afirmação husserliana de que "a palavra 'signo' (Zeichen) teria um 'duplo sentido' (ein Doppelsinn). O signo ‘signo’ pode significar 'expressão' (Ausdruck) ou ‘índice’ (Anzeichen)” (DERRIDA, 1994, p. 10). . Eis a nossa questão, seguindo o argumento derridiano: "[S]erá que a necessidade fenomenológica, o rigor e a sutileza da análise husserliana, as exigências às quais ela responde e às quais devemos antes de mais nada fazer justiça, não dissimulam, entretanto, uma pressuposição metafísica?” (DERRIDA, 1994, p. 10).

\footnotetext{
${ }^{3}$ Cf. E. HUSSERL (2014), Introdução, \$7, p. 17. Aqui, a satisfação de tal princípio equivale à "rigorosa exclusão de todas as asserções que não possam ser completa e totalmente realizadas fenomenologicamente".

${ }^{4}$ Cf. "S 1. Um duplo sentido do termo signo" (HUSSERL, 2014, p. 30).
} 
Pensamos ser suficiente para justificar nosso questionamento a suspeita de que a distinção husserliana acima referida não é isenta de problemas e quiçá esconde "uma aderência dogmática ou especulativa que (...) não reteria a crítica fenomenológica fora de si mesma (...), mas constituiria a fenomenologia em seu íntimo" (DERRIDA, 1994, p. 10), mesmo que, do ponto de vista de Husserl, não tenha um caráter dogmático. Essa distinção é extremamente importante para a consecução de uma filosofia científica isenta de pressupostos - e é por essa mesma razão que questionar tal procedimento torna-se necessário. Antes, porém, de precipitar conclusões, voltemos a Husserl.

O que faz Husserl encontrar uma duplicidade de sentido no termo "signo"? Com efeito, o filósofo observa que "expressão" e "signo" são corriqueiramente tratados como termos unívocos, quando "na linguagem comum, eles de modo algum coincidem em tudo" (HUSSERL, 2014, p. 21). Além disso,

Todo e qualquer signo é signo de qualquer coisa, mas nem todo signo tem uma "significação", um "sentido" que seja "expresso" com o signo. Em muitos casos, não se pode sequer dizer que o signo "designa" aquilo de que é chamado signo. (...) Nomeadamente, signos no sentido de índices (signos caracterizadores, signos distintivos e outros do gênero) não expressam, a não ser que, ao lado da função de indicar, preencham ainda uma função de significação (HUSSERL, 2014, p. 21).

Por tal razão, Husserl observa que "na conversação viva (...) o conceito de indicação aparecerá (...), em comparação com o conceito de expressão, como o conceito mais lato segundo a extensão". Isso não faz dele "gênero em relação ao conteúdo" - pois "[o] significar não é uma espécie do ser-signo no sentido do indicar". Com efeito, a "sua extensão é mais estreita apenas porque o significar - no discurso comunicativo - está sempre entrelaçado com o ser-índice, e este, por sua vez, fundamenta um conceito mais lato, porque pode aparecer precisamente sem um tal entrelaçamento" (HUSSERL, 2014, p. 21).

Ademais, o autor das Investigações lógicas assevera que "As expressões, porém, desempenham a sua função significativa também na vida solitária da alma, onde elas não mais funcionam como índices. $\mathrm{Na}$ verdade, os dois conceitos de signo não estão, portanto, de modo algum, na relação entre um conceito mais lato e um conceito mais estreito" (HUSSERL, 2014, p. 21).

Essa distinção é estabelecida com o intuito de superar os impasses da metafísica através da crítica de seus pressupostos e criar assim as condições adequadas para uma refundação da epistemologia capaz de "levar à clareza e distinção as formas e leis puras do conhecimento, por meio do retorno à intuição adequadamente preenchente” (HUSSERL, 2014, p. 19), esclarecimento ou elucidação esta que deve realizar-se "no quadro de uma fenomenologia do conhecimento, (...) 
dirigida para as estruturas essenciais das vivências 'puras' e para os elementos de sentido que lhe pertencem” (HUSSERL, 2014, p. 19-20). Husserl parte, portanto, de uma desconfiança radical “em relação à pressuposição metafísica [que nesse sentido] já se apresentava como a condição para uma 'autêntica teoria do conhecimento"' (DERRIDA, 1994, p. 11).

Mas tal "projeto de uma teoria do conhecimento - mesmo quando este se livrou, através da 'crítica', desse ou daquele sistema especulativo - não pertencesse logo de saída à história da metafísica”. E se assim é, devemos nos perguntar - com Derrida: “A idéia (sic) do conhecimento e da teoria do conhecimento não é em si metafísica?” (DERRIDA, 1994, p. 11). Talvez tal questão não represente um problema para Husserl. Contudo, tal percurso, da estrutura do signo a uma nova teoria do conhecimento, indique um horizonte no qual a questão metafísica se coloca de modo pertinente, mesmo que o questionamento se distancie da linguagem e argumentação de Husserl.

\section{Distinções fenomenológicas, certeza apodítica e a crítica heideggeriana}

Husserl define as expressões enquanto "signos significativos" - ou, em outros termos, distingue dos signos indicativos aqueles significativos - as expressões. Com isso, pretende excluir diversos usos comuns do termo: não subsume, por exemplo, os usos ordinários do conceito que incluem gestos e demais atos que não digam respeito diretamente à intencionalidade, bem como qualquer outro tipo de atitude em que outros discursos tenderiam a reportar-se ao inconsciente a fim de explicar ou fundamentar seus campos de pesquisa. Derrida encontra aí razões para afirmar o seguinte:

Poderíamos perceber o motivo único e permanente de todos os erros e de todas as perversões que Husserl denuncia na metafísica "degenerada" através de uma multiplicidade de campos, temas e argumentos: há sempre uma espécie de cegueira diante do modo autêntico da idealidade, aquela que é, que pode ser repetida indefinidamente na identidade de sua presença pelo próprio fato de que ela não existe, não é real, é irreal, não no sentido da ficção, mas em outro sentido que poderá receber vários nomes, cuja possibilidade permitirá falar da nãorealidade da essência, do noema, do objeto inteligível e da não-mundanidade geral. Essa não-mundanidade não sendo uma outra mundanidade, essa idealidade não sendo um existente caído do céu, a sua origem será sempre a possibilidade de repetição de um ato produtor. Para que a possibilidade dessa repetição possa abrir-se idealiter ao infinito, é preciso que uma forma ideal assegure essa unidade do indefinidamente e do idealiter: é o presente, ou antes, a presença do presente vivo (DERRIDA, 1994, p. 12)

Heidegger considera precisamente nesse sentido - e nós poderíamos dizer que, na verdade, Derrida deve muito a Heidegger no que diz respeito à elaboração de sua crítica a Husserl - que ao preocupar-se centralmente com o desenvolvimento da ciência, Husserl teorizou (na esteira de 
Descartes) "de um modo peculiar, todos os âmbitos da vida e os modos de ser" ${ }^{5}$. Mas ao mesmo tempo retorna ao mesmo ponto (crítica de Heidegger a Husserl).

Ora, Husserl pretendeu estabelecer uma distinção fenomenológica rigorosa entre as expressões, p. ex. nomes, e o que elas, por um lado, manifestam (vivências psíquicas) e aquilo que elas significam. Mas os nomes são distinguidos também entre o que significam - "o sentido ou 'conteúdo' da representação nominal” - e o que nomeiam, isto é, o próprio “objeto de representação" (HUSSERL, 2014, p. 28). É nesse sentido que Husserl poderá afirmar o seguinte:

Se o caráter essencial da percepção consiste na presunção intuitiva de captar uma coisa ou um processo como presentes eles próprios (...), então a recepção da manifestação é uma simples recepção da manifestação. (...) O ouvinte perceber que o falante exterioriza certas vivências psíquicas e, nessa medida, percebe também essas vivências; mas ele próprio não as vive, não tem delas nenhuma percepção "interna”, mas antes uma percepção "externa”. É a grande diferença entre captar efetivamente um ser na intuição adequada e o captar presuntivo de um ser com base numa representação intuitiva, porém, inadequada. No primeiro caso, é um ser vivido, no último, um ser suposto, a que nenhuma verdade corresponde. A compreensão recíproca exige, precisamente, uma certa correlação dos atos psíquicos, que se desdobram ao longo da manifestação e da recepção da manifestação, mas não exige, de modo algum, a sua completa igualdade (HUSSERL, 2014, p. 29-30).

Mas não estaria essa distinção comprometida em ultima instancia com o projeto epistemológico cartesiano, no sentido de que leva "consigo ulteriores determinações fatais e precisamente fatais para aquilo que na investigação fenomenológica Husserl destaca" "? Heidegger argumenta que a preocupação com a certeza - herança cartesiana - desfigura a interpretação fenomenológica dos resultados quando subordina esta àquela preocupação supramencionada. Isso tem três consequência muito importantes para Heidegger: "1. Com relação à intencionalidade mesma. 2. Acerca do modo de concepção da evidência. 3. A propósito da determinação da investigação fenomenológica como investigação eidética" 7. Assim que Heidegger constata que essas três consequências acima mencionadas constituem três momentos que convergem para um único ponto: "o cogito sum e sua certeza estão vivos em um sentido muito mais fundamental em Husserl, de modo que, neste caso, vem a investigação expressar menos que nunca o caráter de ser da consciência” (HEIDEGGER, 2008, p. 270) ${ }^{8}$.

\footnotetext{
${ }^{5}$ Cf. texto original: “de un peculiar modo, todos los âmbitos de vida y los mundos del ser" (HEIDEGGER, 2008, p. 268). A tradução do trecho aqui citado, bem como as demais neste trabalho, são nossas.

${ }^{6}$ Cf. texto original: "consigo ulteriores determinaciones fatales y precisamente fatales para aquello que em la investigación fenomenológica pone de relieve Husserl” (HEIDEGGER, 2008, 270).

${ }^{7}$ Cf. texto original: "1. Respecto a la intencionalidade mesma. 2. Respecto de como se concibe la evidencia. 3. Respecto de la determinación de la investigación fenomenológica como investigación eidética” (HEIDEGGER, 2008, 270).

${ }^{8}$ Cf. texto original: "el cogito sum y su certitudo están vivos em um sentido mucho más fundamental em Husserl, de modo que, en este caso, viene a investigación expressa menos que nunca el carácter de ser de la conciencia".
} 
Daí "surge a tarefa fundamental de ir pela primeira vez além desta teorização para alcançar novamente, a partir da existência mesma, a possível posição fundamental”" ${ }^{9}$. Heidegger avalia, por conseguinte, a ligação de Husserl com a filosofia cartesiana como algo prejudicial ao projeto fenomenológico, visto que isto mantém Husserl atrelado à compreensão moderna de hypokeimenon "como a auto-certeza do próprio cogito ('ego cogito ergo sum'), ou seja, como o sujeito que põe diante de si todas as coisas que encontra, reduzindo-as todas (...) à condição de objeto de sua representação (Vorstellung)" (DUQUE-ESTRADA, P. C., 2006, p. 60). Com efeito, Heidegger argumenta que "Husserl toma o conceito de consciência simplesmente a partir da psicologia cartesiana e da teoria do conhecimento kantiana. Com elas transmitem-se a totalidade das categorias fundamentais com as quais se caracteriza a consciência; categorias que, de sua parte, não devem sua origem a uma análise deste ser no sentido da investigação de seu modo específico de ser" (HEIDEGGER, 2008, p. 270). ${ }^{10}$.

Husserl parece estar de fato implicado profundamente nas críticas que lhe são endereçadas por Heidegger, pois, ao afirmar "que todos os objetos e relações objetivas apenas são para nós aquilo que são por meio dos atos de visar, deles essencialmente distintos, nos quais eles se tornam representáveis" (HUSSERL, 2014, p. 35), o "mestre" ${ }^{11}$ de Heidegger não mostra sem ambiguidades que sua perspectiva fenomenológica [Husserl] está vigorosamente implicada na crítica de seu "discípulo"? Vejamos a continuação da análise heideggeriana: "[D]e fato, sabe-se que o nomear teórico proporciona certa complexidade ao fundamento da relação intencional, no sentido de que todo juízo, todo querer, todo amar está fundado em um representar, que proporciona o desejável, o odioso, o amável etc. Esta transformação se encontra no fato de que o estudo predominante da intencionalidade é orientado para o intencional no conhecer mesmo (HEIDEGGER, 2008, p. 271) ${ }^{12}$.

\footnotetext{
${ }^{9}$ Cf. texto original: "surge la tarea fundamental de ir por primera vez más allá de esta teorización para alcanzar nuevamente, a partir de la existência misma, la posible posición fundamental” (HEIDEGGER, 2008, p. 268)

${ }^{10}$ Cf. texto original: "Husserl toma el concepto de conciencia simplemente a partir de la psicologia cartesiana y la teoria del conocimiento kantiana. Com ellas se transmitem la totalidade de las categorias fundamentales com las que se caracteriza a la conciencia; categorias que, por su parte, no deben su origen a un análisis de este ser en el sentido de la investigación de su carácter de ser específico".

11 As aspas justificam-se pelo fato de, tanto Husserl quanto Heidegger terem afirmado/reconhecido que o trabalho deste último - quer em termos de âmbito de ocupação temática e seu respectivo campo de objetos, quer no sentido do próprio labor fenomenológico - difere muito da Fenomenologia como fora concebida pelo primeiro [Husserl]. Cf. os $\$ 10$ e $\$ 11$ do livro Facetas heideggerianas (2009), de Ángel Xocolotzi. Outras informações sobre a relação HusserlHeidegger em consonância com as questões que o período histórico impôs a estes pensadores podem ser encontradas em Heidegger e o seu século - Tempo do Ser, tempo da história (1997), de Jeffrey A. Barash.

${ }^{12}$ Cf. texto original: " $[\mathrm{D}] \mathrm{e}$ hecho, se es conciente en general de que el mencionar teorético proporciona el fundamento de toda relación intencional de una certa complejidad, de que todo juicio, todo querer, todo (continuação) amar está fundado en un representar, que proporciona lo deseable, lo odioso, lo amable, etc. Esta transformación se encuentra em el hecho de que el estúdio predominante de la intencionalid se orienta hacia lo intencional en el conocer mismo".
} 
Desse modo, Heidegger observa que Husserl deixa de investigar o caráter específico do ser do homem enquanto Dasein - em sua busca pela certeza apodítica e generalização das investigações científicas para todos os âmbitos da vida e modos de ser, Husserl negligencia o caráter de ser-paraa-morte do Dasein, sua finitude radical, a condição concreta de possibilidade de singularização e autodeterminação para além de um formalismo incapaz de ver no fenômeno da morte mais do que algo a respeito do qual podemos apenas uma certeza empírica, que "permanece aquém do maior grau de certeza, da certeza apodítica, alcançada em esferas do conhecimento teórico" (HEIDEGGER, 2014, p. 333).

Podemos agora perceber as profundas implicações metafísicas da rigorosa distinção fenomenológica, "essencial", entre signo significativo (as expressões) e os signos meramente indicativos - aqueles que sem uma intuição preenchente não podem comunicar nada (cf. seção anterior deste trabalho). Com a crítica heideggeriana/derridiana em mente, podemos fazer nosso o apontamento de Agamben em $A$ linguagem e a morte, de que

A relação essencial entre linguagem e morte tem - para a metafísica - o seu lugar na Voz. Morte e Voz têm a mesma estrutura negativa e são metafisicamente inserparáveis. Ter experiência da morte como morte, significa, efetivamente, fazer experiência da supressão da voz e do surgimento, em seu lugar, de outra Voz [da consciência, em Heidegger] que constitui o originário fundamento negativo da palavra humana. Ter experiência da Voz significa, por outro lado, tornarmo-nos capazes de uma outra morte, que não é mais simplesmente o decesso e que constitui a possibilidade mais própria e insuperável da existência humana, a sua liberdade (AGAMBEN, 2006, p. 118).

Mas em Husserl essa experiência da morte enquanto tal é impossível. Por negligenciar essa relação essencial entre linguagem e morte, Husserl se torna incapaz de perceber a inseparabilidade de Morte e Voz, sua estrutura negativa idêntica.

Ousaríamos dizer que, por não haver possibilidade de estabelecer-se qualquer certeza fundada teoricamente/apoditicamente sobre a morte (que assim não pode portanto ser conquistada pela intuição categorial husserliana), esta escapa à distinção husserliana relativa ao signo. E, dessa forma, o estatuto da morte no pensamento de Husserl apresenta-se como sendo propriamente muito superficial - daí a crueza dos comentários heideggerianos em cartas nas quais discorre sobre a fenomenologia husserliana: numa ocasião chega mesmo a dizer que aquela é "sin sangre" ${ }^{13}$. De fato, segundo Husserl, não podemos representar a morte, isto é, ter uma vivência psíquica - que dirá pura! - da morte. ${ }^{14}$.

\footnotetext{
${ }^{13}$ Cf. trecho de carta enviada a Elfride (p. 53-54) do livro Facetas heideggerianas (2009).

${ }^{14}$ Nesse sentido, Lévinas, em uma nota de rodapé de seu livro Descobrindo a Existência com Husserl e Heidegger (1997), comenta: "Vê-se, uma vez mais, como Husserl permanece fiel ao esquema empirista e à posição equívoca da sensação que pertence, simultaneamente, à esfera do vivido e figura o 'pensado"'(p. 187, Nota 155).
} 


\section{Heidegger, a morte e os limites da representação}

Em Ontologia (Hermenêutica da faticidade), Heidegger acusa a ontologia tradicional por padecer de grave insuficiência - dupla:

1. Desde o princípio seu tema é o ser objetual, a objetualidade de objetualidades determinadas, e objetualidade para um pensar teórico indiferente, ou o ser objetual material para determinadas ciências que se ocupam com ele, da natureza ou da cultura; e o mundo, mas não considerado a partir do [Dasein] ${ }^{15}$ e das possibilidades do [Dasein], porém, sempre através das diversas regiões objetuais; ou fixadas também por outras regiões de caráter não teorético. (...).

2. O que resulta disso: a ontologia bloqueia o acesso ao ente que é decisivo para a problemática filosófica, isto é, ao [Dasein], a partir do qual e para o qual a filosofia é (HEIDEGGER, 2013, p. 9).

Para Heidegger, partindo da faticidade podemos designar o caráter de nosso [Dasein] próprio, de um modo que a ontologia tradicional não permite. "Mais especificamente, a expressão significa: esse [Dasein] em cada ocasião (...), na medida em que é 'aí' em seu caráter ontológico de ser” (HEIDEGGER, 2013, p. 13). Em uma postura abertamente crítica sobretudo com relação a Husserl - embora não mencione o seu nome, Heidegger afirma:

Ser-aí [Dasein] no tocante a seu ser, significa: não e nunca primordialmente enquanto objetualidade da intuição e da determinação intuitiva, da mera aquisição e posse de conhecimentos disso, mas [Dasein] está aí para si mesmo no como de seu ser mais próprio (HEIDEGGER, 2013, p. 13).

A filosofia da existência, como concebida por Heidegger, "pressupõe que todos os conteúdos e verdades tradicionais perderam a sua substância; e, assim, tudo o que resta é facticidade [sic] nua, isto é, o puro facto [sic] da existência (WOLIN, 1998, p. 64). Seu pensamento radicalizase dessa forma por ter clareza "quanto à impossibilidade de modificar simplesmente um programa filosófico por meio de uma determinação diversa do objeto da investigação filosófica e deixando inalterada a maneira segundo a qual o objeto se torna tema” (FIGAL, 2005, p. 31).."

\footnotetext{
${ }^{15}$ A partir daqui, substituiremos "ser-ấ" pela expressão original "Dasein" entre colchetes, a fim de evitar um certo efeito (errôneo) de adinamicidade, que a tradução do termo alemão por "ser-ấ" pode causar. Nas ocasiões em que mencionarmos a $9^{a}$ edição de Ser e tempo (2014), faremos a mesma substituição no caso do termo "presença", utilizado para traduzir "Dasein", posto que tal termo gera ambiguidades com relação, por exemplo, a crítica derridiana que ora discutimos, bem como negligencia o que há de estranho e distante (em suma, indeterminado) no Dasein, em favor do familiar e do próximo (enfatiza a determinação) - ainda que não seja a intenção da tradutora Márcia Schuback.

${ }^{16} \mathrm{O}$ que não quer dizer que a posição teórica assumida por Heidegger esteja isenta de implicações políticas que merecem atenção. Cf. WOLIN, 1998, p. 64-65 e a menção que o autor faz a Karl Löwith e sua interpretação acerca da
} 
A tematização ontológico-existencial do Dasein realizada por Heidegger, nesse sentido, o permite observar, em $O$ conceito de tempo, que a "aporia da apreensão do [Dasein] não se funda na limitação, incerteza e incompletude da faculdade do conhecimento, mas no ente mesmo que deve ser conhecido” (HEIDEGGER, 1997, 22-23). Com efeito, Heidegger ressalta que

\begin{abstract}
Quanto menos pressa houver em passar desapercebidamente por esta aporia, quanto mais tempo nos mantermos nela, tão mais claro será: nisso que para o [Dasein] prepara esta dificuldade ele se mostra na mais extrema possibilidade. $O$ fim do [Dasein], minha morte, não é algo junto a que se completa um conjunto de transcursos, mas uma possibilidade, da qual o [Dasein] sabe duma ou doutra maneira: a extrema possibilidade de si mesmo, que ele pode apreender quando pode assimilá-la antecipadamente. O [Dasein] tem em si mesmo a possibilidade de se encontrar com a sua morte enquanto a extrema possibilidade dele mesmo. Esta extrema possibilidade possui o caráter antecipatório na consciência (Gewisheit), e esta consciência é, por seu lado, caracterizada por meio de uma completa indeterminação. A auto-explicação do [Dasein], que em termos de consciência e autenticidade ultrapassa todo e qualquer enunciado, é a explicação de sua morte, a consciência indeterminada da possibilidade mais própria de estarno-fim (Zu-Ende-seins) (HEIDEGGER, 1997, p. 23).
\end{abstract}

Por essa razão, Heidegger em Ser e tempo afirma que no [Dasein], "enquanto o que está sendo para a sua morte, já está incluído o ainda-não mais extremo de si mesm[o], sobre o qual repousam todos os demais" (HEIDEGGER, 2014, p. 335).

Assim, podemos dizer que Heidegger introduz, através da analítica existencial, "uma maneira de pensar a relação que tenho com o meu eu como um compreender-me de modo prático no mundo" (STEIN, 2003, p. 102). Portanto, enquanto temos por um lado em Husserl uma concepção de morte reduzida à sua significação empírica e extrínseca de acidente humano (DERRIDA, 1994, p. 16), por outro lado, deparamos em Heidegger com a morte enquanto intrinsecamente ligada à condição básica do Dasein enquanto cuidado (Sorge) (HOFFMAN, 1998, p. 218).

A estrutura tríplice do cuidado - ser-adiante-de-si, já-sempre-no-mundo e junto-dos-entes, é designada por Heidegger "com os termos existência, faticidade e decaída. E, nessa estrutura, o elemento central se constitui pela possibilidade diante do ser-para-a-morte, como impossibilidade de qualquer nova possibilidade" (STEIN, 2000, p. 210).

Assim, também a faticidade se dá como a inelutabilidade do ter-que-ser exatamente referido a essa impossibilidade, sem poder repor nada, sem receber a simetria de um objeto, mas apenas o destino da ausência de objeto, da falta (STEIN, 2000, p. 210).

\footnotetext{
"desvalorização total dos significados tradicionais e crenças herdadas" por Heidegger. Embora pertinente, tal assunto foge ao escopo da presente discussão.
}

Cadernos Cajuína, V. 5, N. 2, 2020, p. 37-48. 
Portanto, à pergunta derridiana sobre a possibilidade de o movimento husserliano de idealização - que se constitui enquanto a não-realidade do objeto ideal ou a não-inclusão do sentido ou do noema na consciência e dão a segurança de que a presença na consciência poderá se repetir indefinidamente (Cf. DERRIDA, 1994, p. 16) - consistir em uma relação entre o existente e sua morte. Sendo a "vida transcendental" o palco dessa relação, nós devemos dizer que não poderia ser de outro modo. Afinal, o "Dasein é no tempo, no quotidiano, no histórico e no extático" (HODGE, 1995, p. 296). A concepção epistemológica de conhecimento, desenraizada existencialmente, bem como a "teoretização" da intencionalidade são insuficientes e derivados em relação às possibilidades mais fundamentais do Dasein de que tratamos aqui. 


\section{Referências}

AGAMBEN, G. A linguagem e a morte: um seminário sobre o lugar da negatividade. Belo Horizonte: Editora UFMG, 2006.

BARASH, J. A. Heidegger e o seu século - tempo do Ser, tempo da história. Lisboa: Instituto Piaget, 1997.

DERRIDA, J. A voz e o fenômeno. Rio de Janeiro: Zahar, 1994.

DUQUE-ESTRADA, P. C. Ciência e Pós-representação: Notas sobre Heidegger. In: Política e Trabalho. Revista de Ciências Sociais, ano 22, n. 24 (2006) - João Pessoa: PPGS-UFPB, 2006.

FIGAL, G. Martin Heidegger: fenomenologia da liberdade. Rio de Janeiro: Forense Universitária, 2005.

GUIGNON, C (Dir.). Poliedro Heidegger. Lisboa: Instituto Piaget, 1998.

HEIDEGGER, M. Ser e tempo. Petrópolis: Vozes, 2014. . Ontologia (hermenêutica da faticidade). Petrópolis: Vozes, 2013. . Introducción a la investigación fenomenológica. Madrid: Ed. Sintesis, 2008. O conceito de tempo/ A questão da técnica. In: Cadernos de Tradução, n. 2, DF/USP, 1997.

HODGE, J. Heidegger e a Ética. Lisboa: Instituto Piaget, 1995.

HOFFMAN, P. A morte, o tempo e a história: II parte de O Ser e o tempo. In: Poliedro Heidegger. C. Guignon (Dir.), 1998, p. 213-231.

HUSSERL, E. Investigações lógicas. Rio de Janeiro: Forense, 2014.

LÉVINAS, E. Descobrindo a Existência com Husserl e Heidegger. Lisboa: Instituto Piaget, 1997.

STEIN, E. Diferença e Metafísica. Porto Alegre: EDIPUCRS, 2000.

Nas proximidades da antropologia: ensaios e conferências filosóficas. Ijuí: Ed. Unijuí, 2003.

WOLIN, R. A Política do Ser. Lisboa: Instituto Piaget, 1998.

XOCOLOTZI, Á. Facetas Heideggerianas. Puebla: BUAP/Los libros de Homero, 2009. 